\title{
Knowledge and Practices in Teaching Socio-scientific Issues Among Malaysian Primary School Science Teachers"
}

\author{
Nooraida Yakob, Hashimah Mohd Yunus, Chan Yi May \\ Universiti Sains Malaysia, Penang, Malaysia
}

\begin{abstract}
This research explored primary school science teachers' knowledge and practices in addressing socio-scientific issues (SSIs) for teaching science. Using SSIs-based Instruction Questionnaire (SSIQ), teachers' knowledge and practices on the meaning, approaches, interests, goals, and content knowledge of SSIs were studied. This instrument has been validated by two experts from a university. The reliability of this instrument is 0.974 . There were 867 primary school science teachers from seven states in Malaysia participated in this study. The participants' responses were analyzed by conducting quartile and correlation analysis. The results indicated that the teachers had an average level of knowledge and practices on SSIs. There is a strong positive correlation between their knowledge and practices. Therefore, there is a strong need for science teachers to enhance their knowledge and increase their practices to address SSIs in schools since these issues are pertinent in the 21 st century.
\end{abstract}

Keywords: primary school science education, socio-scientific issues (SSIs), science teacher education

\section{Introduction}

Teaching science using socio-scientific issues (SSIs) supports the development of students' content knowledge, promotes students' interest and motivation to learn science, encourages higher-order thinking skills, and fosters students' decision-making skills (Tal \& Kedmi, 2006). Instead of solely memorizing and recalling of scientific definitions and facts, students identify the controversial SSIs, critically analyze the issues, search and gather information, incorporate their scientific knowledge, communicate and exchange ideas with their peers, make judgments, and generate possible solutions to address the problems (Dolan, Nichols, \& Zeidler, 2009; Lee, Abd-El-Khalick, \& Choi, 2006). In addition, SSIs also help to increase students' engagement in classroom, improve their attitude towards learning science, and maintain their interest in science for their future studies and career (Ekborg \& Ottander, 2010; Lindahl et al., 2010).

After all, extending teaching and learning from the science classroom to society classroom requires teachers to adopt the 21st century science pedagogy using SSIs-based instruction in teaching science. Literature indicates that teacher is one of the important factors that influence the students' performance in a science classroom (Zeidler \& Nichols, 2009). Hence, the main goal of this research is to learn about primary school science teachers' knowledge in addressing controversial SSIs, and also their practices to teach about science using SSIs-based instruction in an elementary science classroom.

\footnotetext{
* Acknowledgment: This work was supported by the Fundamental Research Grant Scheme under Grant 203/PGURU/6711287. Nooraida Yakob, Ph.D., lecturer, School of Educational Studies, Universiti Sains Malaysia. Hashimah Mohd Yunus, Ph.D., associate professor, School of Educational Studies, Universiti Sains Malaysia. Chan Yi May, M.Ed., secondary school teacher, School of Educational Studies, Universiti Sains Malaysia.
} 


\section{Background of the Study}

Various scholars criticized Science-Technology-Society curriculum for typically stressing on the impacts of science and technology on society and ignoring the debates and argumentations over relevant SSIs (Tal \& Kedmi, 2006). As a consequence, it was then the introduction of SSIs in school science education. Unlike the Science-Technology-Society framework which only emphasizes on the interrelationship between science, technology, and society, the SSIs framework provides a broader framework that subsumes all science, technology, and society education has offered (Zeidler \& Nichols, 2009). Besides emphasizing on students' scientific understandings, dealing with SSIs in school science provides teachers with pedagogical strategies that consider both the moral and social development of students.

SSIs are able to relate the learning of science to students' real-life experiences, allow them to apply their knowledge in real-world contexts, and provide them a real meaning of learning (Aligaen \& Mangao, 2012). Studies show that teacher characteristics, practices, knowledge, and experiences have positive relationship with students' performance and achievement (Darling-Hammond, 1999; Goe \& Stickler, 2008; Supovitz \& Turner, 2000). In order for teachers to teach SSI, teachers are at least expected to have knowledge in SSIs and able to practice it. Thus, understand about the meaning of SSIs, note the approaches of the controversial issues, recognize the interests of introducing real-world issues in the learning process, know the goals of SSIs-based instruction, and aware of the current issues that are being discussed (Bartholomew, Osborne, \& Ratcliffe, 2004; Kara, 2012; Lee et al., 2006), teachers can be expected to deliver scientific knowledge effectively and meaningfully to each student if they are able to introduce SSIs in science classes (Dolan et al., 2009).

The above studies indicate that teacher's knowledge is of great importance to determine the effectiveness of a teacher in a science classroom (Ekborg, Ideland, \& Malmberg, 2009; Bartholomew et al., 2004). From the literature, it was found that there are five main components that bring out the knowledge and practice of a teacher in teaching science using SSIs. They are: (a) the meaning of SSIs; (b) the approaches of the real world issues; (c) the interests of using the issues in the teaching and learning process; (d) the goals of integrating SSIs in a science classroom; and (e) the content knowledge of SSIs (Zeidler, Sadler, Simmons, \& Howes, 2005; Facione, 2010; Zeidler \& Nichols, 2009; Çavas, Holbrook, Kask, \& Rannikmae, 2013).

Sadler, Amirshokoohi, Kazempour, and Allspaw's (2006) research found that there is a teacher who rejects the idea that ethics play a role in science and opposes to teach any ethical or social issues in a science classroom. According to this participant, science is about learning "facts" and not about ethics. Clearly, different teachers have different interpretations of the meaning of science. Besides the meaning of science, teachers also have different interpretations of the meaning of SSIs. For instance, some teachers view SSIs as the results of human misuse of science and technology (Lee et al., 2006). On the other hand, some teachers define SSIs as issues that are "a natural consequence of the nature of science" (Kara, 2012, p. 115).

It brings out the questions of how teachers interpret and practice the meaning of science and SSIs. Ekborg and Ottander (2010) found that teachers talked about the importance of applying scientific knowledge and have the ideas of connecting school science to the real world, but it seems like that they are not clear about it, and they are unable to provide any examples. This is closely related to the knowledge of teachers about the concept of SSIs in teaching science. 
A number of studies have found that many teachers consider SSIs are important in science education because the lines between society and science can hardly be separated (Ekborg \& Ottander, 2010; Kara, 2012; Lee et al., 2006). However, literature indicates that there are some teachers who comment that they are unfamiliar and unprepared to manage arguments or debates over controversial issues during science lessons (Sadler et al., 2006). Besides that, they also argue that conducting discussion, argument, or debate during science lessons is time-consuming (Simonneaux, 2007). Indeed, there are also many teachers who hold strong beliefs that their most important goal and responsibility is to teach facts and certainties (Simonneaux, 2007). They are interested in the ability of their students to reproduce the scientific facts rather than the ability to construct the idea about science (Bartholomew et al., 2004; Lindahl et al., 2010).

Previous studies indicate that some teachers perceive that they are not ready and do not have the sufficient content knowledge and expertise to handle the multidisciplinary issues (Kara, 2012; Lee et al., 2006). This is because in order to address the controversial issues in science classes, it requires teachers to have a broad range of knowledge, such as economics, politics, ethics, technology, health, and environment (Ekborg et al., 2009). In addition, teachers indicate that these issues can cause conceptual difficulties to teachers and students (Hestness, McGinnis, Riedinger, \& Marbach-Ad, 2011). Teachers believe that students can be easily distracted if they are dealing with complex argumentations over controversial issues (Zeidler et al., 2005). These imply that teachers lacked knowledge in SSIs. As a result, it is difficult for them to practice discussions and argumentations over SSIs in reality.

The purpose of this study is to examine the knowledge and practices of primary school science teachers in teaching science using SSIs. Thus, this study specificaly would like to learn about their knowledge and practices of the meaning, approaches, interests, goals, and content knowledge of SSIs. The study was conducted based on the following objectives:

1. Determine the knowledge and practices of primary school science teachers in teaching science using SSIs;

2. Examine the correlation between teachers' knowledge and practices in teaching science using SSIs.

\section{Methodology}

This study employed a survey design via stratified sampling. There were 1,360 primary school science teachers who were involved in this study from various states in Malaysia, namely, Sabah, Penang, Kedah, Perlis, Terengganu, Kelantan, and Johor. Out of 1,360 teachers of science, 867 (63.8\% response rate/rate of return) of them participated in the study. Gay, Mills, and Airasian (2011) mentioned that the best response rate is $50 \%$ of the total sample. If the response rate is more than $50 \%$, that finding can increase the confidence level for the survey and was representative of the population in general. A SSIs-based Instruction Questionnaire (SSIQ) was used in this study. There are 42 questions in this instrument with five sections: (a) the meaning of SSIs; (b) approaches of SSIs in teaching and learning science; (c) the importance of using SSIs in science classes; (d) the goals of integrating SSIs into school science; and (e) the content knowledge of SSIs. A 5-point Likert scale was used in this study: "Strongly agree", "Agree", "Slightly agree", "Disagree", and "Strongly disagree". Table 1 shows the reliability value for each construct.

Data were analyzed by using quartile with the scales of "High", "Average", and "Low" knowledge and practices. Pearson's correlation coefficient was also used to measure the strength of correlation between the knowledge and practice in SSIs. 
Table 1

Cronbach's Alpha Coefficients According to Constructs in the Questionnaire

\begin{tabular}{lllr}
\hline \multirow{2}{*}{ Construct } & \multicolumn{2}{c}{ Cronbach's alpha } & Item \\
\cline { 2 - 4 } & Knowledge & Practice & 5 \\
Meaning & 0.746 & 0.902 & 10 \\
Approach & 0.898 & 0.942 & 12 \\
Interest & 0.923 & 0.959 & 9 \\
Goal & 0.912 & 0.945 & 6 \\
Content knowledge & 0.848 & 0.872 & 42 \\
Reliability & 0.947 & 0.974 & \\
\hline
\end{tabular}

\section{Findings and Discussion}

\section{Teachers' Knowledge and Practices}

Three levels of categories are used, i.e., "Low", "Medium", and "High". Mean value for all SSI constructs for knowledge is $172.62 \pm 15.80$. Therefore, the categorised level is based on the quartile value, i.e., mean value \pm 1 standard deviation (see Table 2).

Table 2

Scale of the Level of Knowledge

\begin{tabular}{|l|l|l|}
\hline Quartile value & Level & Explaination \\
\hline Below 156.82 & Low & Extensive knowledge (know about all the five sections) \\
\hline $156.83-188.41$ & Medium & Moderate knowledge (know about three to four sections) \\
\hline Above 188.42 & High & Limited knowledge (know about one to two sections) \\
\hline
\end{tabular}

Findings showed that $86(11.1 \%)$ teachers have a low level of SSI knowledge, which means that they have limited knowledge on the issues and only know about one to two sections of SSIs. While $573(73.7 \%)$ teachers have a medium level of SSI knowledge, which implies that they are considered to have a moderate level of knowledge on the issues. Instead of knowing all the five sections about SSIs, teachers in this group only know about three to four sections of SSIs. However, 119 (15.3\%) teachers have a high level knowledge on SSIs, which means that they have extensive knowledge on the controversial issues and know about all five sections about SSIs (see Table 3).

Table 3

Teachers' Level of Knowledge

\begin{tabular}{lcc}
\hline Knowledge level on SSIs & $N$ & Percent (\%) \\
\hline Low level & 86 & 11.1 \\
Medium level & 573 & 73.7 \\
High level & 119 & 15.3 \\
Total & 778 & 100 \\
\hline
\end{tabular}

In terms of teachers' practices, teachers who have a mean value greater than 171.77 are classified in a high level of practice on SSIs. They have regular implementation and practice all the five sections about SSIs frequently. For teachers with a moderate level of practice in addressing SSIs, the range of the mean value is from 130.85 to 171.77 . Teachers who have moderate practices are those who practice three to four sections of SSIs sporadically. Further, for the mean value which is less than 130.85, the teachers are placed in low level of 
practice in integrating SSIs in science classrooms. They have limited practices in dealing with the real-world issues to teach about science (see Table 4).

Table 4

Scale of the Level of Practice

\begin{tabular}{|l|l|l|}
\hline Quartile value & Level & Explaination \\
\hline Below 171.77 & Low & Regular practices (practice all the five sections frequently) \\
\hline $130.85-171.76$ & Medium & Moderate practices (practice three to four sections sporadically) \\
\hline Above 130.86 & High & Limited practices (little or practice only one to two sections) \\
\hline
\end{tabular}

Findings show that $126(14.5 \%)$ teachers have a low level of practice in working with SSIs, $612(70.65 \%)$ teachers have a moderate level of practice in addressing the real-world controversial issues, and 129 (14.95\%) teachers have a high level of practice in using SSIs to teach about science (see Table 5).

Table 5

Teachers' Level of Practice

\begin{tabular}{llc}
\hline Level & $N$ & Percent (\%) \\
\hline Low & 126 & 14.5 \\
Average & 612 & 70.6 \\
High & 129 & 14.9 \\
Total & 867 & 100.0 \\
\hline
\end{tabular}

The majority of the teachers in this study have an average level of knowledge on the issues and an average level of practice in addressing the controversial issues in their science classrooms. As the results shown, they do not have a deep knowledge and understanding on the meaning of SSIs. Besides that, the respondents note that they do not have a strong knowledge on the content of the complex SSIs, and do not practice the multidisciplinary issues frequently. Among the five sections about SSIs, they only know about three to four sections and practice three to four sections about the issues sporadically. Similar to the teachers in the other studies (Ekborg \& Ottander, 2010; Lee et al., 2006), the participants are not clear about the meaning, approaches, interests, goals, and content knowledge of SSIs and have moderate practices in handling the real-world issues to teach about science. The participants in this study perceive themselves as lacking of extensive content knowledge on the multidisciplinary issues, and express less practice in integrating the interesting contents of the issues into their science classes.

\section{Correlation Between Teachers' Knowledge and Practices}

Pertaining to the relationship between teachers' knowledge and practices in addressing SSIs for teaching science, a Pearson product-moment correlation coefficient is computed to learn regarding the strength of correlation between the two variables. The results show that there is a significant correlation between teachers' knowledge and practices in the population $\left(r_{(867)}=0.62 ; p<0.05\right)$. Overall, there is a positive, high correlation between teachers' knowledge and practices. A stronger knowledge, which teachers have on SSIs, is correlated with a higher rate of practices in addressing the real-life issues in science classrooms (see Table 6).

Meanwhile, due to the complex and controversial nature of SSIs, many teachers in the previous studies show low confidence in their ability (Lee et al., 2006; Sadler et al., 2006; Simonneaux, 2007) and tend to avoid 
addressing the issues in class (Hestness et al., 2011; Lee et al., 2006; Sadler et al., 2006) even though they have the knowledge and perceive the issues to be important and worthwhile. Also, they express many constraints that hinder them from addressing the issues in classrooms (Aligaen \& Mangao, 2012; Hestness et al., 2011; Lee et al., 2006; Saunders \& Rennie, 2013). With reference to the prior studies, many of the researchers perceive that there is a disconnection between teachers' knowledge on SSIs and their practices in addressing the issues (Hestness et al., 2011; Lee et al., 2006; Sadler et al., 2006). In contrast, in this research, the result shows that there is a significant, positive correlation between teachers' knowledge and practices. They reflect what they know into practices in real classroom situations.

Table 6

Correlations

\begin{tabular}{llcc}
\hline & & Knowledge & Practice \\
\hline \multirow{3}{*}{ Knowledge } & Pearson correlation & 1 & $0.615^{*}$ \\
& Sig. (2-tailed) & - & 0.000 \\
& $N$ & 867 & 867 \\
Practice & Pearson correlation & $0.615^{*}$ & 1 \\
& Sig. (2-tailed) & 0.000 & - \\
\hline
\end{tabular}

Note. ${ }^{*}$ Significant at the 0.05 level.

\section{Conclusion}

It is suggested by many educational researchers that integrating real-life SSIs is essential in today's science education (Aligaen \& Mangao, 2012; Zeidler et al., 2005). According to the researchers, learning that occurs within real-world, social context is able to prepare students with the knowledge and skills needed in the 21 st century. Thus, there is a need for teachers to teach school science using the real-world issues. Furthermore, teaching primary school science using SSIs is important to make young learners familiar with science, and to retain their knowledge and interest in science by connecting the learning to their real-life experiences (Dolan et al., 2009). Towards the aim of creating an interactive and meaningful learning environment, teachers need to have an extensive knowledge on SSIs and practice the issues frequently (Zeidler et al., 2009). Knowing and practicing, meaning, approaches, interests, goals, and content of SSIs are crucial in order to handle the issues effectively.

\section{References}

Aligaen, J. C., \& Mangao, D. D. (2012). Climate change integrated education: A model for lifelong learning system. Paper presented at The International Conference on Educating the Future We Want: A Green Southeast Asia. Retrieved from http://www.apn-gcr.org/resources/archive/files/eb93169ba7a38fbdd95329ba7ba075ad.pdf

Bartholomew, H., Osborne, J., \& Ratcliffe, M. (2004). Teaching students "ideas-about-science": Five dimensions of effective practice. Science Education, 88(5), 655-682.

Çavas, B., Holbrook, J., Kask, K., \& Rannikmae, M. (2013). Development of an instrument to determine science teachers' implementation of inquiry based science education in their classrooms. International Online Journal of Primary Education, 2(2), 9-22. Retrieved from http://www.iojpe.org

Darling-Hammond, L. (1999). Teacher quality and student achievement: A review of state policy evidence. Seattle, W.A.: Center for the Study of Teaching and Policy, University of Washington.

Dolan, T. J., Nichols, B. H., \& Zeidler, D. L. (2009). Using socioscientific issues in primary classrooms. Journal of Elementary Science Education, 21(3), 1-12. 
Ekborg, M., \& Ottander, C. (2010). Working with socio-scientific issues. Students' and teachers' experiences. Paper presented at The XIV Symposium of the International Organization for Science and Technology Education (IOSTE). Retrieved from http://dspace.mah.se/handle/2043/13094

Ekborg, M., Ideland, M., \& Malmberg, C. (2009). Science for life-A conceptual framework for construction and analysis of socio-scientific cases. Nordic Studies in Science Education, 5(1), 35-46.

Facione, P. A. (2010). Critical thinking: What it is and why it counts. Millbrae, C.A.: Insight Assessment, Measured Reasons and The California Academic Press. Retrieved from http://www.student.uwa.edu.au/_data/assets/pdf_file/0003/1922502/ Critical-Thinking-What-it-is-and-why-it-counts.pdf

Gay, L. R., Mills, G. E., \& Airasian, P. (2011). Educational research: Competencies for analysis and applications (10th ed.). Columbus, O.H.: Pearson.

Goe, L., \& Stickler, L. M. (2008). Teacher quality and student achievement: Making the most of recent research (TQ Research \& Policy Brief). National Comprehensive Center for Teacher Quality.

Hestness, E., McGinnis, J. R., Riedinger, K., \& Marbach-Ad, G. (2011). A study of teacher candidates' experiences investigating global climate change within an elementary science methods course. Journal of Science Teacher Education, 22(4), 351-369.

Kara, Y. (2012). Pre-service biology teachers' perceptions on the instruction of socio-scientific issues in the curriculum. European Journal of Teacher Education, 35(1), 111-129.

Lee, H., Abd-El-Khalick, F., \& Choi, K. (2006). Korean science teachers' perceptions of the introduction of socio-scientific issues into the science curriculum. Canadian Journal of Math, Science \& Technology Education, 6(2), 97-117.

Lindahl, B., Rosberg, M., Ekborg, M., Ideland, M., Malmberg, C., Rehn, A., ... Winberg, M. (2010). Socio-scientific issues-A way to improve students' interest and learning? Paper presented at The NARST Annual International Conference, Philadelphia. Retrieved from http://www.sisc.se/Materiel/Lindahl\%20et\%20al.pdf

Sadler, T. D., Amirshokoohi, A., Kazempour, M., \& Allspaw, K. M. (2006). Socioscience and ethics in science classrooms: Teacher perspectives and strategies. Journal of Research in Science Teaching, 43(4), 353-376.

Saunders, K. J., \& Rennie, L. J. (2013). A pedagogical model for ethical inquiry into socioscientific issues in science. Research in Science Education, 43(1), 253-274.

Simonneaux, L. (2007). Argumentation in socio-scientific contexts. In S. Erduran, \& M. P. Jiménez-Aleixandre (Eds.), Argumentation in science education: Perspectives from classroom-based research (pp. 179-200). Netherlands: Springer.

Supovitz, J. A., \& Turner, H. M. (2000). The effects of professional development on science teaching practices and classroom culture. Journal of Research in Science Teaching, 37(9), 963-980.

Tal, T., \& Kedmi, Y. (2006). Teaching socioscientific issues: Classroom culture and students' performances. Cultural Studies of Science Education, 1(4), 615-644.

Zeidler, D. L., \& Nichols, B. H. (2009). Socioscientific issues: Theory and practice. Journal of Elementary Science Education, 21(2), 49-58.

Zeidler, D. L., Sadler, T. D., Applebaum, S., \& Callahan, B. E. (2009). Advancing reflective judgment through socioscientific issues. Journal of Research in Science Teaching, 46(1), 74-101.

Zeidler, D. L., Sadler, T. D., Simmons, M. L., \& Howes, E. V. (2005). Beyond STS: A research-based framework for socioscientific issues education. Science Education, 89(3), 357-377. 